\title{
New Detector Based on Composite of Carbon Nanotubes with Nanoparticles of Cobalt Oxide for Carbohydrates Analysis by HPLC with Reverse Pulsed Amperometric Detection
}

\author{
Acelino C. de Sá, ${ }^{a}$ Leonardo L. Paim ${ }^{b}$ and Nelson R. Stradiotto ${ }^{\circledR *, a, c, d}$ \\ ${ }^{a}$ Instituto de Química, Universidade Estadual Paulista (Unesp), 14800-060 Araraquara-SP, Brazil \\ ${ }^{b}$ Câmpus Experimental de Rosana, Universidade Estadual Paulista (Unesp), \\ 19273-000 Rosana-SP, Brazil \\ 'Instituto de Pesquisa em Bioenergia, Universidade Estadual Paulista (Unesp), \\ 13500-230 Rio Claro-SP, Brazil \\ ${ }^{d}$ Escola de Engenharia Industrial e Metalúrgica de Volta Redonda (EEIMVR), \\ Universidade Federal Fluminense (UFF), 27255-125 Volta Redonda-RJ, Brazil
}

\begin{abstract}
This work aims to present an alternative detector for the determination of arabinose, galactose, glucose and xylose in hydrolyzed sugarcane bagasse. The detector was developed using an electrode modified with multi-walled carbon nanotubes containing cobalt oxide nanoparticles (GCE/MWCNT/CoOOH) applied in high-performance liquid chromatography (HPLC) with reverse pulsed amperometric detection (RPAD). The limits of detection obtained were $3.4 \times 10^{-6}$, $4.4 \times 10^{-6}, 3.6 \times 10^{-6}$ and $5.0 \times 10^{-6} \mathrm{~mol} \mathrm{~L}^{-1}$ for arabinose, galactose, glucose and xylose, respectively. The standard addition method was used to determine the concentration of sugars in the hydrolyzed sugarcane. The determined concentrations for arabinose, galactose, glucose, and xylose were $1.0 \times 10^{-3}, 7.2 \times 10^{-5}, 3.0 \times 10^{-3}$ and $2.4 \times 10^{-3} \mathrm{~mol} \mathrm{~L}^{-1}$, respectively. The results demonstrate that this new method can be used for the detection of sugars without the interference of other electroactive species.
\end{abstract}

Keywords: sugarcane bagasse, second generation ethanol, HPLC-RPAD, carbon nanotubes, cobalt oxide nanoparticles

\section{Introduction}

Carbohydrates are among the most important naturally occurring biomolecules, and are regarded a vital source of food in the food industry as well as a potential source of fuel in the fuel industry. ${ }^{1}$ The outstanding properties and usefulness of carbohydrates in alternative energy and biomass have contributed to its growing importance among researchers in the area. These organic compounds represent the major component of biomass, and it is believed that around $20 \%$ of all manufactured chemicals will come from biomass by $2020 .^{2}$ The compounds can be used as alternative to chemicals derived from fossil fuels, ${ }^{3}$ while biomass waste may also be converted into fuel, chemicals and other commodity materials. ${ }^{4,5}$

*e-mail: nrstradi@gmail.com
The methods employed for the determination of carbohydrates are found to be essentially relevant because these compounds are widely used in the food and pharmaceutical industries, apart from their usefulness as precursors in the production of chemicals and biofuel. ${ }^{6-10}$ In view of that, it has become, undoubtedly, crucial to develop efficient analytical methods with high precision and limits of detection suitable for routine analyses and determination of carbohydrates. The main goal is to help reduce industrial losses and contribute toward the optimization and control of processes aiming at generating high value-added products. ${ }^{11}$

Among the wide range of methods reported in the literature, high performance liquid chromatography (HPLC) stands out when it comes to carbohydrates determination in biomass samples. Several detectors coupled to HPLC have been used for this purpose, these include refractive index detector, ${ }^{7}$ spectrophotometric 
detector, ${ }^{12}$ capillary electrophoresis detector, ${ }^{13,14}$ evaporative light scattering detector, ${ }^{15}$ mass spectroscopy detector, ${ }^{16}$ high-performance liquid chromatography with dual detectors, diode array detector and refractive index ${ }^{8}$ and electrochemical detectors (pulsed amperometric detection). ${ }^{17-19}$

Refractive index (RI) detection is found to be susceptible to co-elution of non-object compounds that are present in the samples, in addition to being unsuitable for gradient elution and sensitive to small temperature changes..$^{19}$ Electrochemical detector equipped to pulsed amperometric detector (PAD) has some advantages, these include selectivity, due to pulsed amperometric detection, and sensibility. ${ }^{19,20}$ Rodríguez-Gómez et al. ${ }^{19}$ studied a simple and reliable method for the determination of fructooligosaccharides (FOS), kestose (GF2), nystose (GF3), and fructofuranosylnystose (GF4) in the presence of fructose, glucose and lactose in dairy products. Their proposed HPLC-RI method exhibited limits of quantification (LOQ) 100 times higher than those of the high-performance anion-exchange chromatography (HPAEC)-PAD method. The HPLC-RI method requires the analysis of samples with concentration of analytes superior to $0.1 \mathrm{mg} \mathrm{mL}^{-1}$.

Gangola et al..$^{20}$ developed a reliable and rapid method for the analysis of soluble sugars and raffinose family oligosaccharides in chickpea using HPAEC-PAD and HPLC-RI techniques. The results showed that HPAEC-PAD exhibited higher sensitivity and shorter run time compared to HPLC-RI when it comes to analyzing the members of raffinose family oligosaccharides and other soluble sugars. The HPAEC-PAD method has been successful at separating glucose, fructose, sucrose, raffinose, stachyose and verbascose in $35 \mathrm{~min}$.

The electrochemical detector is based on a threeelectrode electrochemical cell. One of the outstanding merits of this detector is the possibility of modifying the working electrode as required. For example, the use of electrodes modified with metal nanoparticles for nonenzymatic electrochemical detection of carbohydrates is an alternative to unmodified electrodes. ${ }^{21-23}$ Furthermore, some substrates, including metal substrates $\mathrm{Au}, \mathrm{Ag}$ and $\mathrm{Pt}$ ), carbon electrodes, ${ }^{24}$ boron-doped diamond electrodes $(\mathrm{BDD})^{25}$ and carbon nanotube electrodes (CNT), are seen to be more adequate for surface modification. ${ }^{26,27}$ Bearing this in mind, the present work sought to develop a new method for carbohydrates detection based on glassy carbon electrode modified with carbon nanotubes containing nanoparticles of cobalt oxide (GCE/MWCNT/CoOOH) applied for the determination of carbohydrates in sugarcane bagasse samples.

\section{Experimental}

\section{Reagents and solutions}

Cobalt(II) chloride hexahydrate $\left(\mathrm{CoCl}_{2} \cdot 6 \mathrm{H}_{2} \mathrm{O}, 99 \%\right)$, $\mathrm{N}$ - $\mathrm{N}$-dimethylformamide $\left(\mathrm{C}_{3} \mathrm{H}_{7} \mathrm{NO}, 99.8 \%\right)$, D-glucose $\left(\mathrm{C}_{6} \mathrm{H}_{12} \mathrm{O}_{6}, 99 \%\right)$, D-galactose $\left(\mathrm{C}_{6} \mathrm{H}_{12} \mathrm{O}_{6}, 99 \%\right)$, L-arabinose $\left(\mathrm{C}_{5} \mathrm{H}_{10} \mathrm{O}_{5}, 99 \%\right)$ and D-xylose $\left(\mathrm{C}_{5} \mathrm{H}_{10} \mathrm{O}_{5}, 99 \%\right)$ were purchased from Sigma-Aldrich (St. Louis, MO, USA). All solutions were prepared using deionized water purified in a Milli-Q system with resistivity of no less than $18.2 \mathrm{M} \Omega \mathrm{cm}$ at $25^{\circ} \mathrm{C}$. Purified multi-walled carbon nanotubes (MWCNTs) with an outer diameter of 6-9 nm were purchased from Sigma-Aldrich (St. Louis, MO, USA). Phosphate buffer ( $\mathrm{pH}$ 6.5) was prepared using $30 \mathrm{~mL}$ of $0.10 \mathrm{~mol} \mathrm{~L}^{-1} \mathrm{Na}_{2} \mathrm{HPO}_{4}$ and $70 \mathrm{~mL}$ of $0.10 \mathrm{~mol} \mathrm{~L}^{-1} \mathrm{NaH}_{2} \mathrm{PO}_{4}$. The sugar solutions were prepared shortly before usage.

Instrumentation

Electrochemical experiments were carried out using potentiostat/galvanostat Autolab PGSTAT-30 controlled by general purpose electrochemical system (GPES) software (Metrohm, Utrecht, The Netherlands). A conventional cell with three electrodes was used, where GCE/MWCNT/ $\mathrm{CoOOH}$ was used as the working electrode (geometric area $\left.=0.070 \mathrm{~cm}^{2}\right), \mathrm{Ag} / \mathrm{AgCl}\left(\mathrm{KCl}, 3.0 \mathrm{~mol} \mathrm{~L}^{-1}\right)$ as reference electrode and platinum wire $(3.0 \mathrm{~cm} \times 0.1 \mathrm{~cm})$ as auxiliary electrode. Prior to undertaking all electrochemical experiments, the electrochemical cell was saturated with nitrogen for $15 \mathrm{~min}$. All experiments were performed at room temperature.

GCE/MWCNT/CoOOH electrode was characterized by scanning electron microscopy (SEM) and energy-dispersive $\mathrm{X}$-ray (EDX). The analysis was carried out using a scanning electron microscope with cannon electron emission field (SEM-FEG), model JSM (Jeol, Inc., Peabody, USA). ImageJ software ${ }^{28}$ was used to measure the size of the nanoparticles. For the analysis of the modified electrodes, glassy carbon plates with a total area of $1.0 \mathrm{~cm}^{2}$ and a thickness of $0.20 \mathrm{~cm}$ with a covered area of $0.070 \mathrm{~cm}^{2}$ were used.

Chromatographic measurements were conducted with the aid of 850 Professional IC (Metrohm, Utrecht, The Netherlands), controlled by MagicNet software, equipped with extender module 872 (post-column) and an autosampler 863-Compact Autosampler (Metrohm, Utrecht, The Netherlands). An RPAD with electrochemical cell in wall-jet configuration was used (945 professional detector Vario ion chromatography (IC) amperometric, Metrohm, Utrecht, The Netherlands). The cell was 
composed of platinum $(\mathrm{Pt})$ as auxiliary electrode, palladium (Pd) as reference electrode and GCE/MWCNT/CoOOH as working electrode. The chromatographic separation was performed using DIONEX ${ }^{\circledR}$ CarboPac PA $1(250 \times 4 \mathrm{~mm}$ internal diameter) column coupled to CarboPac PA 1 guard column $(50 \times 4 \mathrm{~mm}$ internal diameter $)$.

\section{Modification of GCE surface with MWCNT and cobalt oxide nanoparticles}

The surface of the glassy carbon electrode (GCE) was cleaned by polishing with $0.3 \mu \mathrm{m}$ alumina powder (Merck, Darmstadt, Germany) and rinsed in ethanol and deionized water. Prior to the modification of the GCE surface, the MWCNTs were functionalized. An amount of $2.0 \mathrm{~g}$ of MWCNT was ultra-sonicated for $4.0 \mathrm{~h}$ in a mixture of $60.0 \mathrm{~mL}$ of $\mathrm{H}_{2} \mathrm{SO}_{4}\left(18.0 \mathrm{~mol} \mathrm{~L}^{-1}\right)$ and $20.0 \mathrm{~mL}$ $\mathrm{HNO}_{3}\left(16.0 \mathrm{~mol} \mathrm{~L}^{-1}\right)$. After sonication, the MWCNTs were filtered through of a polytetrafluorethylene (PTFE) membrane of $5.0 \mu \mathrm{m}$ and washed with deionized water until the $\mathrm{pH}$ of the supernatant reached 6.0. After washing and neutralization, the MWCNTs were dried in oven for $12 \mathrm{~h}$ at $80{ }^{\circ} \mathrm{C}$. The main purpose of functionalization is to generate functional groups $-\mathrm{COOH}$ on the surface of the MWCNTs which act as nucleation sites that allow one to obtain smaller particles and higher dispersions. ${ }^{29}$ For the electrode surface modification with MWCNTs, a suspension of $1.0 \mathrm{mg}$ of MWCNT functionalized in $10.0 \mathrm{~mL} \mathrm{~N}, N$-dimethylformamide (DMF) was prepared by sonication for $30 \mathrm{~min}$. The volume of $5.0 \mu \mathrm{L}$ of homogeneous MWCNT suspension was dropped onto the GCE surface, and the coating was thereafter dried at $50{ }^{\circ} \mathrm{C}$ for $2.0 \mathrm{~h}$.

Subsequently, the GCE modified with MWCNT was electrochemically modified with cobalt nanoparticles by electrodeposition in a solution of $1.0 \times 10^{-3} \mathrm{~mol} \mathrm{~L}^{-1}$ $\mathrm{CoCl}_{2} \cdot 6 \mathrm{H}_{2} \mathrm{O}$ in phosphate buffer ( $\mathrm{pH}$ of 6.0 ). The electrodeposition was carried out by cyclic voltammetry; this involved 30 successive cycles of -1.1 to $1.2 \mathrm{~V}$ versus $\mathrm{Ag} / \mathrm{AgCl}$ at $100 \mathrm{mV} \mathrm{s}^{-1}$. After that, the GCE/MWCNT containing cobalt nanoparticles was subjected to 45 successive cycles of -0.3 to $0.7 \mathrm{~V}$ versus $\mathrm{Ag} / \mathrm{AgCl}$ at $50 \mathrm{mV} \mathrm{s}^{-1}$ in $0.1 \mathrm{~mol} \mathrm{~L}^{-1} \mathrm{NaOH}$ to enable the formation of cobalt oxide species. ${ }^{30,31}$ Thereafter, the GCE/MWCNT containing cobalt oxide nanoparticles (GCE/MWCNT/ $\mathrm{CoOOH}$ ) was rinsed with deionized water.

\section{Preparation of the hydrolyzed sugarcane bagasse}

Sugarcane bagasse was obtained from a sugar and alcohol industry in the Araraquara region (São Paulo,
Brazil). Biomass hydrolysis was carried out according to the method employed by the National Renewable Energy Laboratory (NREL). ${ }^{32}$ First, the sugarcane bagasse was placed in a Soxhlet apparatus for the removal of extractives. Initially, water was used to remove aqueous extractives, and ethanol was subsequently used for the removal of ethanolic extracts. After that, the remaining solid was dried at $40{ }^{\circ} \mathrm{C}$ (overnight). Samples of $300 \mathrm{mg}$ of this solid were transferred to a flask of $250 \mathrm{~mL}$, and $3.0 \mathrm{~mL}$ of $\mathrm{H}_{2} \mathrm{SO}_{4} 72 \%(\mathrm{v} / \mathrm{v})$ were added to the mixture. The mixture was kept under vigorous stirring in a thermostatic bath at $45^{\circ} \mathrm{C}$ for $60 \mathrm{~min}$. The hydrolysis reaction was halted by the addition of $85.0 \mathrm{~mL}$ of deionized water. For the complete hydrolysis of the remaining oligomers, the mixture was autoclaved at $120{ }^{\circ} \mathrm{C}$ and at 1.05 bar for $60 \mathrm{~min}$. The final mixture was neutralized via the addition of $\mathrm{CaCO}_{3}$. Subsequently, the mixture was filtered twice through of a polytetrafluorethylene (PTFE) membrane of pore diameter of $0.45 \mu \mathrm{m}$ was used for the first filtration, and the second filtration was performed with a pore diameter membrane filter of $0.22 \mu \mathrm{m}$.

\section{Chromatographic measurements}

The mobile phase was constituted by $91 \%$ of deionized water and $9 \%$ of $0.10 \mathrm{~mol} \mathrm{~L}^{-1} \mathrm{NaOH}$ at flow of $1.0 \mathrm{~mL} \mathrm{~min}^{-1}$. During the chromatographic runs, the flow of $0.30 \mathrm{~mL} \mathrm{~min}^{-1}$ of $0.300 \mathrm{~mol} \mathrm{~L}^{-1} \mathrm{NaOH}$ was maintained in extender module 872 in order to keep the ionic strength constant in the detector. Injection volume was set at $25 \mu \mathrm{L}$. The temperatures of the column oven and the amperometric detector were kept constant at 25 and $35^{\circ} \mathrm{C}$, respectively, during the experiments. The potential pulse applied for the RPAD technique was composed of four stages: $0.58 \mathrm{~V}$ (versus $\mathrm{Pd}$ ) for $200 \mathrm{~ms}\left(\mathrm{E}_{1}\right), 0.10 \mathrm{~V}$ (versus $\mathrm{Pd}$ ) for $50 \mathrm{~ms}\left(\mathrm{E}_{2}\right) ; 0.70 \mathrm{~V}$ (versus $\mathrm{Pd}$ ) for $50 \mathrm{~ms}\left(\mathrm{E}_{3}\right)$ and $0.58 \mathrm{~V}$ (versus $\mathrm{Pd}$ ) for $50 \mathrm{~ms}\left(\mathrm{E}_{4}\right)$.

\section{Results and Discussion}

\section{Electrochemical behavior}

Figure 1a shows 30 cyclic voltammograms during the electrodeposition on the GCE/MWCNT/Co electrode in phosphate buffer solution of $0.1 \mathrm{~mol} \mathrm{~L}^{-1}(\mathrm{pH} 6.5$ ) containing $1.0 \times 10^{-3} \mathrm{~mol} \mathrm{~L}^{-1}$ of cobalt chloride $\left(\mathrm{CoCl}_{2}\right)$. As can be observed, there is a cathodic peak at $-1.0 \mathrm{~V}$ (peak I) in the first scan; this peak is related to equation 1. The cathodic peak (I) decreases as the number of cycles is increased; this indicates that the $\mathrm{Co}^{\mathrm{II}}$ ion was slowly reduced on the cobalt oxide layer deposited on the surface 
of the glassy carbon electrode modified with carbon nanotubes.

An anodic peak was observed at $-0.30 \mathrm{~V}$ versus $\mathrm{Ag} / \mathrm{AgCl}$ (peak II), this peak is related to the dissolution of the cobalt layer deposited on the surface of the electrode..$^{30,33}$

It is worth noting that no oxidation peaks were observed relative to the $\mathrm{Co}(\mathrm{OH})_{2}$ or $\mathrm{Co}_{3} \mathrm{O}_{4}$ species formed at potentials less than $1.05 \mathrm{~V}$ versus $\mathrm{Ag} / \mathrm{AgCl}$. Nonetheless, an oxidation peak was observed at the potential of $1.05 \mathrm{~V}$ versus $\mathrm{Ag} / \mathrm{AgCl}$ along with an increase in current related to the evolution of oxygen (peak III) which can be attributed to the formation of $\mathrm{CoOOH}$ (equations 2-3). Cathodic peak currents (peak IV) at potential of $0.85 \mathrm{~V}$ versus $\mathrm{Ag} / \mathrm{AgCl}$ correspond to the reduction of $\mathrm{CoOOH}$ to $\mathrm{Co}(\mathrm{OH})_{2}$ or $\mathrm{Co}_{3} \mathrm{O}_{4} \cdot{ }^{30,33}$

$\mathrm{Co}^{2+}+2 \mathrm{e}^{-} \rightarrow \mathrm{Co}^{0}(\mathrm{~s})$

$\mathrm{Co}(\mathrm{OH})_{2}+\mathrm{OH}^{-} \rightleftharpoons \mathrm{CoOOH}+\mathrm{H}_{2} \mathrm{O}+\mathrm{e}^{-}$

$\mathrm{Co}_{3} \mathrm{O}_{4}+\mathrm{H}_{2} \mathrm{O}+\mathrm{OH}^{-} \rightleftharpoons 3 \mathrm{CoOOH}+\mathrm{e}^{-}$

The behavior of the GCE/MWCNT/CoOOH electrode is shown in Figure 1b. One will notice that it is a relatively complex behavior because these species have several oxidation states with different varieties of cobalt oxides and hydroxides present in the region of the potential investigated.

The hydrated species of $\mathrm{Co}^{\mathrm{II}}$ are gradually converted into species containing $\mathrm{Co}^{\mathrm{III}}$, which include $\mathrm{Co}_{3} \mathrm{O}_{4}$, $\mathrm{Co}_{2} \mathrm{O}_{3}, \mathrm{Co}(\mathrm{OH})_{2}$, and different crystallographic forms of $\mathrm{CoOOH}$ species are simultaneously present under these experimental conditions. ${ }^{34,35}$

Studies carried out with X-ray photoelectrons in cobalt oxide/hydroxide showed a detailed structure, indicating

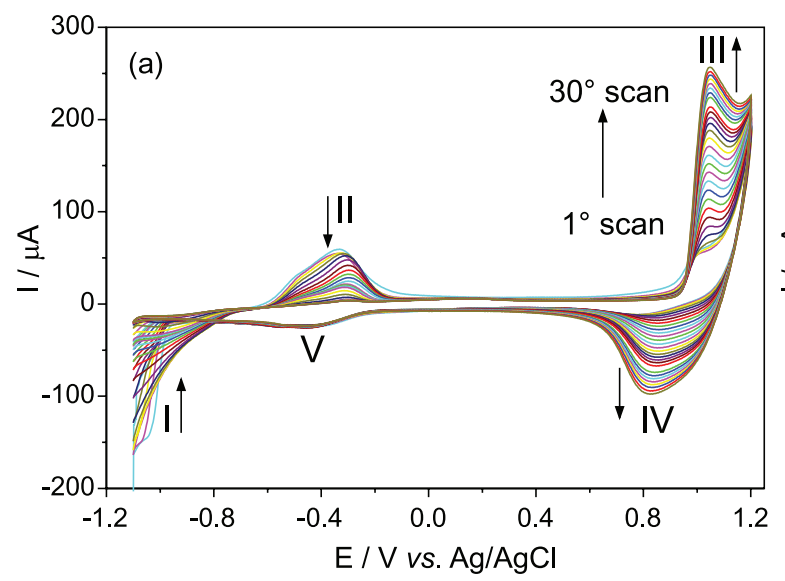

the simultaneous presence of various species of oxide/ hydroxide of $\mathrm{Co}^{\mathrm{II}}$ and $\mathrm{Co}^{\mathrm{III}}$ on the surface of the electrode. ${ }^{35}$

The most relevant species of cobalt oxide/hydroxide are related to the composition of the solution and the applied potentials. Figure $1 \mathrm{~b}$ presents cyclic voltammogram in solution of $\mathrm{NaOH} 0.1 \mathrm{~mol} \mathrm{~L}^{-1}$, where three sets of peaks were obtained. The peaks are Ia, IIa/IIc and IIIa/IIIc, and were obtained at potentials of $0.07,0.24$ and $0.56 \mathrm{~V}$ versus $\mathrm{Ag} / \mathrm{AgCl}$, respectively.

Peak Ia presented an irreversible behavior, which is most often not reported in the literature. This behavior can be attributed to the overlap of peak Ia with the redox pair IIa/IIc. Furthermore, the intensity of peak Ia can be reduced if the potential window is restricted to potential of $+0.15 \mathrm{~V}$ versus $\mathrm{Ag} / \mathrm{AgCl}$. This peak potential can probably be attributed to the electrochemical transition involving hydrated $\mathrm{Co}^{\mathrm{II}}$ forming intermediate species of cobalt oxide, $\mathrm{Co}_{3} \mathrm{O}_{4},{ }^{34}$ according to equation 4 .

$3 \mathrm{Co}(\mathrm{OH})_{2}+2 \mathrm{OH}^{-} \rightleftharpoons \mathrm{Co}_{3} \mathrm{O}_{4}+4 \mathrm{H}_{2} \mathrm{O}+2 \mathrm{e}^{-}$

The peaks of redox potential IIa/IIc can be attributed to the oxy-reduction of cobalt during the conversion of $\mathrm{Co}_{3} \mathrm{O}_{4} / \mathrm{CoOOH}$, leading to the formation of the oxide hydroxide species of cobalt(III) as shown in equation 5 . The behavior observed in the peaks of redox potential IIIa/IIIc can be associated with the oxy-reduction process of $\mathrm{CoOOH} / \mathrm{CoO}_{2}$, where $\mathrm{Co}{ }^{\mathrm{III}}$ is oxidized to $\mathrm{Co}^{\mathrm{IV}}$, based on equation $6 ;^{33,34}$ these species are responsible for the oxidation of carbohydrates on the surface of the GCE/MWCNT/CoOOH electrode.

$\mathrm{Co}_{3} \mathrm{O}_{4}+\mathrm{OH}^{-}+\mathrm{H}_{2} \mathrm{O} \rightleftharpoons 3 \mathrm{CoOOH}+\mathrm{e}^{-}$

$\mathrm{CoOOH}+\mathrm{OH}^{-} \rightleftharpoons \mathrm{CoO}_{2}+\mathrm{H}_{2} \mathrm{O}+\mathrm{e}^{-}$

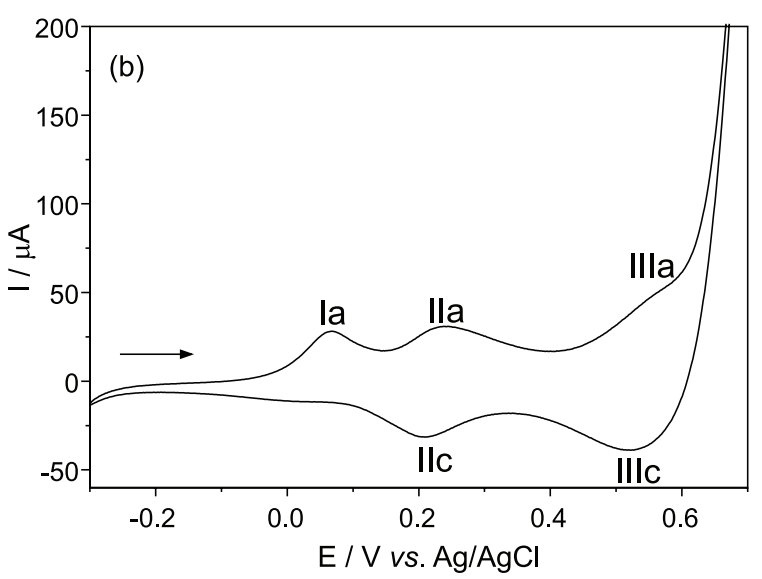

Figure 1. (a) Consecutive cyclic voltammograms for the formation of cobalt nanoparticles on glassy carbon electrode modified with carbon nanotubes in $0.1 \mathrm{~mol} \mathrm{~L}^{-1}$ of phosphate buffer solution ( $\left.\mathrm{pH} 6.5\right)$ containing $1.0 \times 10^{-3} \mathrm{~mol} \mathrm{~L}^{-1}$ of cobalt chloride $\left(\mathrm{CoCl}_{2}\right)$ (scan rate $\left.50 \mathrm{mV} \mathrm{s}^{-1}\right)$. (b) Voltammetric behavior of GCE/MWCNT/CoOOH electrode $\left(0.1 \mathrm{~mol} \mathrm{~L}-1 \mathrm{NaOH}\right.$; scan rate $\left.50 \mathrm{mV} \mathrm{s}^{-1}\right)$. 

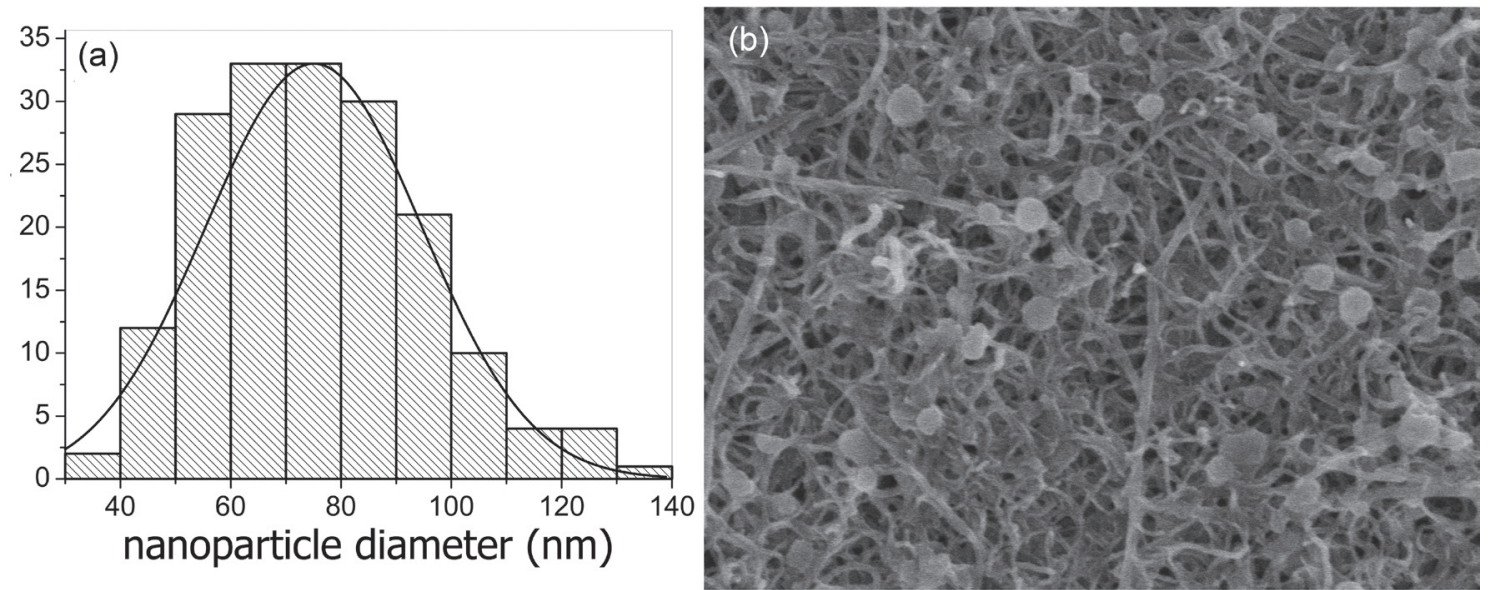

Figure 2. (a) Particle size histogram of the GCE/MWCNT/CoOOH electrode; (b) SEM image of GCE/MWCNT with magnification of 50.000 times.

\section{Characterization of GCE/MWCNT/CoOOH}

The glassy carbon electrode modified with carbon nanotubes and the glassy carbon electrode modified with carbon nanotubes containing cobalt nanoparticles (MWCNT/CoOOH) were studied by comparing the images of the surfaces in various magnifications of micrograph images generated by SEM-FEG.

In Figure S1a of the Supplementary Information (SI) section, one will observe that the carbon nanotubes are dispersed on the GCE surface. As the nanotubes are randomly scattered, this dispersion can act as adsorption sites for the nanoparticles in these tangled carbon nanotubes. Figure S1b shows the details of the nanotubes with the diameter of around 10 to $20 \mathrm{~nm}$; this is consistent with the manufacturer's specifications.

The histogram depicting the size of the nanoparticles is presented in Figure 2a. Here, one notices that most of the nanoparticles that were subjected to characterization display sizes between 50 and $100 \mathrm{~nm}$ in diameter with a mean of $75.1 \pm 19.6 \mathrm{~nm}$.

Figure $2 b$ shows the image of the GCE/MWCNT/ $\mathrm{CoOOH}$ electrode surface. In this figure, one will observe that the nanoparticles display a spherical pattern and are dispersed on the surface of carbon nanotubes. This dispersion behavior seen throughout the electrode surface may result in improvements in detection and quantification of the analytes, while further increasing the stability and detectability of the electrode when applied in HPLC-RPAD.

The chemical characterization using dispersive energy spectroscopy (EDS) technique exhibited in the SI section (Figure S2) shows intense carbon peaks due to the presence of the glassy carbon used as substrate and carbon nanotubes of the modified electrode; the presence of oxygen and cobalt peaks is an indication that the modification occurred effectively over the course of the formation of cobalt oxide.

\section{Electro-oxidation of carbohydrates}

The electro-oxidation of carbohydrates (arabinose, galactose, glucose e xylose) on the GCE/MWCNT/ $\mathrm{CoOOH}$ electrode is shown in Figure 3. As can be seen in the figure, instead of a peak, one notices the formation of an anodic wave at a potential around $0.58 \mathrm{~V}$ versus $\mathrm{Ag} /$ $\mathrm{AgCl}$ and a decrease in the cathodic peak current. The electro-oxidation of carbohydrates on GCE/MWCNT/ $\mathrm{CoOOH}$ occurs in the presence of the $\mathrm{Co}^{\mathrm{IV}}$ catalyst through an active redox mediator unit. During the carbohydrate oxidation process, the catalyst is reduced to $\mathrm{Co}^{\mathrm{III}}$ and the formation of ketones occurs prior to the evolution of oxygen, based on equation 7. In this case, glucose is oxidized via electrochemical-chemical (EC) mechanism. ${ }^{30}$ The other sugars presented patterns of behavior similar to glucose..$^{34,35}$

$2 \mathrm{CoO}_{2}+$ D-Glucose $\rightarrow 2 \mathrm{CoOOH}+$ Gluconolactone

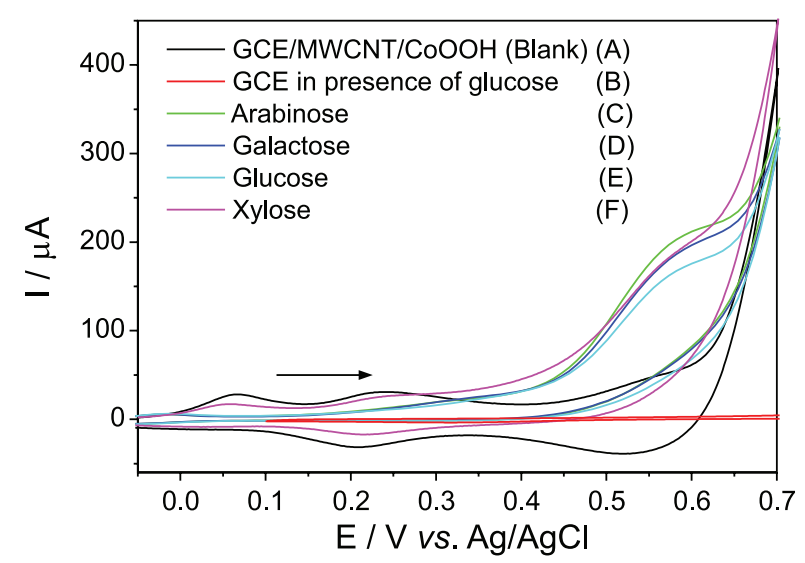

Figure 3. Cyclic voltammograms of GCE/MWCNT/CoOOH in the (a) absence (blank), (b) CGE in the presence of $2.0 \times 10^{-3} \mathrm{~mol} \mathrm{~L}^{-1}$ of glucose and GCE/MWCNT/CoOOH in the presence of $2.0 \times 10^{-3} \mathrm{~mol} \mathrm{~L}^{-1}$ of (c) arabinose, (d) galactose, (e) glucose and (f) xylose in $0.1 \mathrm{~mol} \mathrm{~L}^{-1}$ $\mathrm{NaOH}\left(50 \mathrm{mV} \mathrm{s}^{-1}\right)$. 


\section{Optimization of chromatographic parameters}

The reverse pulsed amperometric detection (RPAD) technique is performed with a sequence of potentials after the application of the oxidation potential of carbohydrates (shown in Figure S3, SI section). Below is a detailed description of the pulse programming:

First pulse $\left(\mathrm{E}_{1}\right)$ : the duration of this pulse is $250 \mathrm{~ms}$, and the potential applied is $0.58 \mathrm{~V}$ versus $\mathrm{Pd}$. The first $50 \mathrm{~ms}$ are used for the conditioning of the GCE/MWCNT/CoOOH electrode. It is worth noting that when the potential in the range of 0 to $50 \mathrm{~ms}$ is applied, the electrode current is not recorded in the chromatogram; the system records the data related to the electrode current in the chromatogram only when the potential applied is within the range of 50 to $200 \mathrm{~ms}$. Second pulse $\left(\mathrm{E}_{2}\right)$ : a potential pulse of $0.10 \mathrm{~V}$ versus $\mathrm{Pd}$ for $50 \mathrm{~ms}$ is applied aiming at the total reduction of all the species absorbed on the surface of the electrode. During the application of this potential pulse, the electrode current is not recorded in the chromatogram. Third pulse $\left(\mathrm{E}_{3}\right)$ : the duration of this pulse is $50 \mathrm{~ms}$. A positive potential of $0.70 \mathrm{~V}$ versus $\mathrm{Pd}$ is applied aiming at the oxidization of all cobalt species on the surface of the electrode and for the formation of $\mathrm{Co}^{\mathrm{IV}}$ which plays a key role in the oxidation of carbohydrates. During the application of this potential pulse, the electrode current is not recorded in the chromatogram. Fourth pulse $\left(\mathrm{E}_{4}\right)$ : this potential pulse of $0.58 \mathrm{~V}$ versus $\mathrm{Pd}$ is applied for $50 \mathrm{~ms}$ aiming at initiating the stabilization of the electrode for posterior oxidation of carbohydrates. During the application of this potential pulse, the electrode current is not recorded in the chromatogram.

This cycle of potentials is repeated throughout the chromatographic measurements. The potentials applied in the RPAD are important for the monitoring of carbohydrates, since these potentials exert a direct influence over the resolution of the chromatograms.

In order to obtain the best potential programming of the pulse sequence used for the determination of carbohydrates, the pulses applied in the oxidation of the carbohydrates via the reverse pulsed amperometric detection were optimized.

The carbohydrate selected for this study was arabinose. The study showed that the peak area for arabinose increases as the potential increases up to $0.58 \mathrm{~V}$ versus $\mathrm{Pd}$ (shown in Figure S4, SI section), where the potential remains constant up to $0.60 \mathrm{~V}$ versus $\mathrm{Pd}$. At potentials above this value, the peak area tends to decrease, indicating that the $\mathrm{Co}^{\mathrm{IV}}$ species are not electroactive at higher potentials. Furthermore, the potential of $0.58 \mathrm{~V}$ versus $\mathrm{Pd}$. was found to be the best analysis potential for the studies involving the application of the GCE/MWCNT/CoOOH electrode. The potential of $0.60 \mathrm{~V}$ was not selected due to the studies related to the steady state. In this region of the potential, the discharge produced by oxygen contributed to an increase in current and, consequently, resulted in an increase in the area of the peak in the chromatogram.

The optimization of the separation method for carbohydrates was carried out in order to evaluate the composition of the mobile phase relative to the retention time. Figure S5 (SI section) shows the chromatograms with the carbohydrates based on studies of six mobile phase conditions, which included the following: $\left(\mathrm{A}-100 \% \mathrm{H}_{2} \mathrm{O}\right)$; (B - $1 \%$ of $0.1 \mathrm{~mol} \mathrm{~L}^{-1} \mathrm{NaOH}$ and $99 \%$ of $\left.\mathrm{H}_{2} \mathrm{O}\right)$; (C $-5 \%$ of $0.1 \mathrm{~mol} \mathrm{~L}^{-1} \mathrm{NaOH}$ and $95 \%$ of $\mathrm{H}_{2} \mathrm{O}$ ); (D - $9 \%$ of $0.1 \mathrm{~mol} \mathrm{~L}^{-1}$ $\mathrm{NaOH}$ and $91 \%$ of $\left.\mathrm{H}_{2} \mathrm{O}\right)$; ( $\mathrm{E}-10 \%$ of $0.1 \mathrm{~mol} \mathrm{~L} \mathrm{~L}^{-1} \mathrm{NaOH}$ and $90 \%$ of $\left.\mathrm{H}_{2} \mathrm{O}\right)$; and $\left(\mathrm{F}-15 \%\right.$ of $0.1 \mathrm{~mol} \mathrm{~L}^{-1} \mathrm{NaOH}$ and $85 \%$ of $\mathrm{H}_{2} \mathrm{O}$ ).

The chromatograms are presented according to each mobile phase composition. In Figures S5a-c, a greater separation is observed between the peaks, where one notices an enlargement of the peaks and a significant increase in the retention time. This behavior is attributed to a possible larger interaction of the analytes with the column.

However, for the chromatograms shown in Figures S5d-f, a decrease is observed in the retention time, but the chromatograms e and $\mathrm{f}$ presented a relatively smaller separation between the peaks and a decrease in resolution. With regard to the mobile phase chosen for the development of the analytical method, the chromatogram shown in Figure S5d was found to be the best pattern of behavior in terms of separation - with composition of mobile phase of $9 \%$ of $0.1 \mathrm{~mol} \mathrm{~L}^{-1} \mathrm{NaOH}$ and $91 \%$ of $\mathrm{H}_{2} \mathrm{O}$.

In general, the elution sequence (see Table 1, data from Figure 4) of these compounds is associated with the $\mathrm{pH}$ value of approximately 10 . The neutral carbohydrates do not undergo deprotonation, and, as such, they do not interact with the column by an anion exchange mechanism. The separation phenomena must, therefore, be based on ion-dipole interaction. The order of separation and elution is related to the parameters that influence the separation: hydroxyl groups number, anomerism, positional isomerism and degree of polymerization. ${ }^{18}$ These parameters can be applied when it comes to separation with water. As the concentration of the mobile phase is increased with $\mathrm{OH}$ species, these species bind to the column, diminishing the interaction of the $\mathrm{OH}$ groups of the sugars with the column. The decline in interaction leads to a reduction of the retention time and an increase in the output velocity of the column analytes, reaching the point of decreasing the resolution. In view of that, the mobile phase of $9 \%$ of $\mathrm{NaOH}$ with $91 \%$ of $\mathrm{H}_{2} \mathrm{O}$ was chosen. 
Table 1. Molecular structure, pKa value, retention time, resolution and number of theoretical plates for the bohydrates (data from Figure 4)

\begin{tabular}{|c|c|c|c|c|c|}
\hline Carbohydrate & Molecular structure & $\mathrm{p} K \mathrm{a}^{\mathrm{a}}$ & Retention time / min & Resolution & $\begin{array}{c}\text { Number of theoretical } \\
\text { plates }\end{array}$ \\
\hline D-(-)-Arabinose & $\mathrm{OH}$ & 12.43 & 10.70 & 4.64 & 6632 \\
\hline D-(+)-Galactose & OH & 12.35 & 13.37 & 2.55 & 7532 \\
\hline D-(+)-Glucose & & 12.28 & 14.95 & 3.51 & 8806 \\
\hline D-(+)-Xylose & $\mathrm{OH} \mathrm{OH}$ & 12.15 & 17.13 & 8.54 & 12554 \\
\hline
\end{tabular}

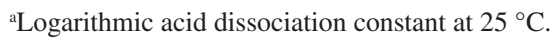

Figure 4 shows the chromatogram with standard solutions of arabinose, galactose, glucose and xylose using GCE/MWCNT/CoOOH electrode as the electrochemical detector. The proposed method favored a good separation between the peaks of the carbohydrates.

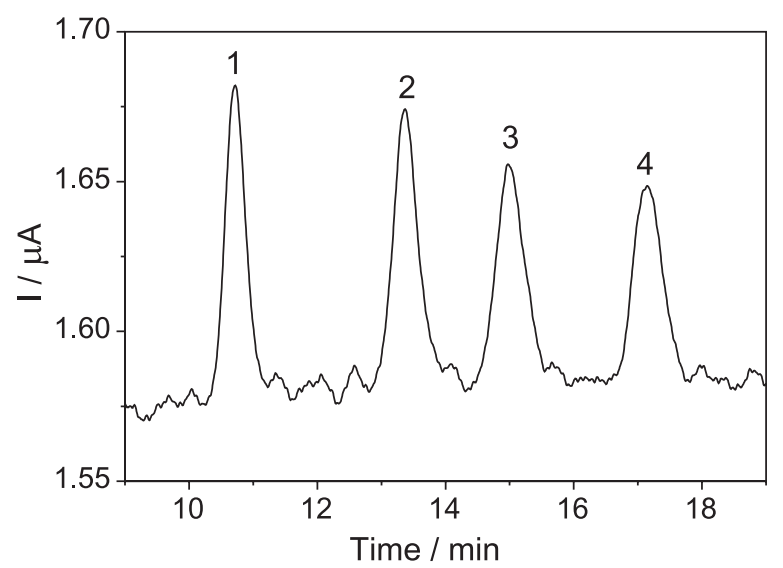

Figure 4. Chromatograms of carbohydrates (1) arabinose, (2) galactose, (3) glucose and (4) xylose in $4.0 \times 10^{-5} \mathrm{~mol} \mathrm{~L}^{-1}$. Detection potential of $0.58 \mathrm{~V}$ versus $\mathrm{Pd}$ for the GCE/MWCNT/CoOOH electrode, mobile phase composition of $9 \%$ of $0.1 \mathrm{~mol} \mathrm{~L}^{-1} \mathrm{NaOH}$ and $91 \%$ of $\mathrm{H}_{2} \mathrm{O}$, flow of mobile phase $1.0 \mathrm{~mL} \mathrm{~min}{ }^{-1}$, column oven temperature of $25^{\circ} \mathrm{C}$, detector temperature of $35^{\circ} \mathrm{C}$.

The calibration curves were constructed with the aim of evaluating the figures of merit of the GCE/MWCNT/CoOOH-based HPLC-RPAD technique.
The experiments were carried out with standard solutions of the concentrations ranging from $1.1 \times 10^{-5}$ to $1.0 \times 10^{-4} \mathrm{~mol} \mathrm{~L}^{-1}$ aiming at evaluating the limits of detection (LOD), quantification (LOQ) and the amperometric sensitivity (AS) of the HPLC-RPAD.

For arabinose, the LOD and LOQ obtained were $3.4 \times 10^{-6}$ and $1.1 \times 10^{-5} \mathrm{~mol} \mathrm{~L}^{-1}$, respectively; and the AS obtained was $1.2 \times 10^{6} \mathrm{~A} \mathrm{~L} \mathrm{~mol}^{-1}$, this was calculated based on the regression equation $y=-2.85+1.18 \times 10^{6} x$. For galactose, the LOD and LOQ obtained were $4.4 \times 10^{-6}$ and $1.4 \times 10^{-5} \mathrm{~mol} \mathrm{~L}^{-1}$, respectively; and the AS obtained was $1.5 \times 10^{6} \mathrm{~A} \mathrm{~L} \mathrm{~mol}^{-1}$, this was calculated based on the regression equation $y=-2.70+1.52 \times 10^{6} x$. For glucose, the LOD and LOQ obtained were $3.6 \times 10^{-6}$ and $1.1 \times 10^{-5} \mathrm{~mol} \mathrm{~L}^{-1}$, respectively; and the AS obtained was $1.3 \times 10^{6} \mathrm{~A} \mathrm{~L} \mathrm{~mol}^{-1}$, this was calculated based on the regression equation $y=5.26+1.34 \times 10^{6} x$. Finally, for xylose, the LOD and LOQ obtained were $5.0 \times 10^{-6}$ and $2.1 \times 10^{-5} \mathrm{~mol} \mathrm{~L}^{-1}$; and the AS obtained was $0.9 \times 10^{6} \mathrm{~A} \mathrm{~L} \mathrm{~mol}^{-1}$.

Table 2 shows the results obtained for the GCE/ MWCNT/CoOOH-based HPLC-RPAD technique compared to those of other chromatography methods reported in the literature. One will notice that the chromatographic methods using derivatization with trimethylsilylation (TMS), alditol acetate and fluorescent reagents obtained much closer detection limits compared 
to the GCE/MWCNT/CoOOH-based HPLC-RPAD technique. Furthermore, sample preparation based on derivatization renders the technique less applicable to the quantification of large sample sets. The HPLC-RPAD technique can significantly reduce sample preparation time compared to chromatography with derivatization. This is because, in the case of the latter, one needs to execute many steps apart from the large number of manual processing steps involved. The greater number of steps involved makes the procedure involving chromatography with derivatization time-consuming and tedious to perform.
A further drawback that is worth pointing out is that derivatization suffers from instability due to the presence of moisture. Aside the instability, the method involving derivatization also yields multiple peaks for a given sugar as a result of the anomeric preservation prevalent throughout the procedure. ${ }^{36}$ The HPLC-RPAD technique has an advantage over the reverse phase chromatography because the former leads to relatively faster and more efficient separation of complex carbohydrate mixtures compared to the latter. Electrochemical detection allows the selective measurement of electroactive species, paving the

Table 2. Comparison of the detection and quantification limits for some methods reported in the literature involving carbohydrates determination

\begin{tabular}{|c|c|c|c|c|}
\hline Type of technique & Analyte & $\mathrm{LOD} /\left(\mathrm{mol} \mathrm{L}^{-1}\right)$ & $\mathrm{LOQ} /\left(\mathrm{mol} \mathrm{L}^{-1}\right)$ & Reference \\
\hline \multirow{4}{*}{$\begin{array}{l}\text { HPLC-fluorescence with } \\
\text { derivatization }\end{array}$} & galacose & $55.6 \times 10^{-9}$ & $\mathrm{NS}^{\mathrm{a}}$ & \multirow{4}{*}{37} \\
\hline & arabinose & $79.9 \times 10^{-9}$ & $\mathrm{NS}^{\mathrm{a}}$ & \\
\hline & glucose & $55.6 \times 10^{-9}$ & $\mathrm{NS}^{\mathrm{a}}$ & \\
\hline & xylose & $55.6 \times 10^{-9}$ & $\mathrm{NS}^{\mathrm{a}}$ & \\
\hline \multirow{4}{*}{$\begin{array}{l}\text { HPAEC-fluorescence with } \\
\text { derivatization }\end{array}$} & arabinose & $3.3 \times 10^{-6}$ & $8.6 \times 10^{-6}$ & \multirow{4}{*}{38} \\
\hline & galactose & $5.5 \times 10^{-6}$ & $1.9 \times 10^{-5}$ & \\
\hline & glucose & $3.9 \times 10^{-6}$ & $1.4 \times 10^{-5}$ & \\
\hline & xylose & $3.3 \times 10^{-6}$ & $1.0 \times 10^{-5}$ & \\
\hline \multirow{4}{*}{$\begin{array}{l}\text { HPAEC-UV-Vis with } \\
\text { derivatization }\end{array}$} & arabinose & $3.3 \times 10^{-7}$ & $1.0 \times 10^{-6}$ & \multirow{4}{*}{39} \\
\hline & galactose & $3.3 \times 10^{-7}$ & $1.0 \times 10^{-6}$ & \\
\hline & glucose & $6.1 \times 10^{-7}$ & $1.8 \times 10^{-6}$ & \\
\hline & xylose & $3.3 \times 10^{-7}$ & $1.0 \times 10^{-6}$ & \\
\hline \multirow{4}{*}{$\begin{array}{l}\text { Gas chromatography with } \\
\text { alditol acetate derivatization }\end{array}$} & arabinose & $3.3 \times 10^{-6}$ & $\mathrm{NS}^{\mathrm{a}}$ & \multirow{4}{*}{36} \\
\hline & galactose & $2.7 \times 10^{-6}$ & $\mathrm{NS}^{\mathrm{a}}$ & \\
\hline & glucose & $2.7 \times 10^{-6}$ & $\mathrm{NS}^{\mathrm{a}}$ & \\
\hline & xylose & $1.7 \times 10^{-6}$ & $\mathrm{NS}^{\mathrm{a}}$ & \\
\hline HPLC-RID & glucose & $0.3 \times 10^{-3}$ & $1.0 \times 10^{-3}$ & 40 \\
\hline \multirow{4}{*}{ HPAEC-PAD } & arabinose & $1.5 \times 10^{-4}$ & $\mathrm{NS}^{\mathrm{a}}$ & \multirow{4}{*}{36} \\
\hline & galactose & $1.3 \times 10^{-4}$ & $\mathrm{NS}^{\mathrm{a}}$ & \\
\hline & glucose & $6.5 \times 10^{-5}$ & $\mathrm{NS}^{\mathrm{a}}$ & \\
\hline & xylose & $1.4 \times 10^{-4}$ & $\mathrm{NS}^{\mathrm{a}}$ & \\
\hline \multirow{4}{*}{ HPAEC-PAD } & arabinose & $9.3 \times 10^{-5}$ & $3.1 \times 10^{-4}$ & \multirow{4}{*}{38} \\
\hline & galactose & $1.8 \times 10^{-5}$ & $5.3 \times 10^{-5}$ & \\
\hline & glucose & $1.6 \times 10^{-5}$ & $5.5 \times 10^{-5}$ & \\
\hline & xylose & $1.2 \times 10^{-5}$ & $3.9 \times 10^{-5}$ & \\
\hline \multirow{4}{*}{$\begin{array}{l}\text { HPLC-RPAD GCE/MWCNT/ } \\
\mathrm{CoOOH}\end{array}$} & arabinose & $3.4 \times 10^{-6}$ & $1.1 \times 10^{-5}$ & \multirow{4}{*}{ this work } \\
\hline & galactose & $4.4 \times 10^{-6}$ & $1.4 \times 10^{-5}$ & \\
\hline & glucose & $3.6 \times 10^{-6}$ & $1.1 \times 10^{-5}$ & \\
\hline & xylose & $5.0 \times 10^{-6}$ & $2.1 \times 10^{-5}$ & \\
\hline
\end{tabular}

${ }^{a}$ Non-specified; LOD: limit of detection; LOQ: limit of quantification; HPLC: high performance liquid chromatography; HPAEC: high performance anion exchange chromatography; HPAEC-UV-VIS: high performance anion exchange chromatography with UV-Vis detection; HPLC-RID: high performance liquid chromatography with refractive index detector; HPAEC-PAD: high performance anion exchange chromatography with pulsed amperometric detector; HPLC-RPAD GCE/MWCNT/CoOOH: high-performance liquid chromatography with reverse pulsed amperometric detection using glassy carbon electrode modified with multi-walled carbon nanotubes containing cobalt oxide nanoparticles. 
way for many interfering species to pass through the system undetected, once they cannot be oxidized or reduced. ${ }^{36}$

Figure 5 shows the calibration curve with a good linearity for arabinose, galactose, glucose and xylose. The linear correlation coefficients are close to 0.999 .

The samples of sugarcane bagasse were subjected to hydrolysis, neutralization and filtration. Samples of hydrolyzed sugarcane bagasse were injected into the HPLC-RPAD based GCE/MWCNT/CoOOH detector under optimized conditions; the identification of the chromatographic peaks was carried out based on the retention time of each analyte and confirmed by the addition of standard solution. Figure 6 shows the chromatogram for the concentrated sample, where the presence of arabinose, galactose, glucose and xylose can be detected.

The standard addition method was used to determine the concentration of carbohydrates present in the hydrolyzed sugarcane bagasse. This method is particularly important when the sample is very complex, as is the case of sugarcane bagasse. The curve of the standard addition method for arabinose presented the regression equation $y=23.0+1.6 \times 10^{6} x$, with a linear correlation of 0.998 ; the sample dilution was performed 70 times because the
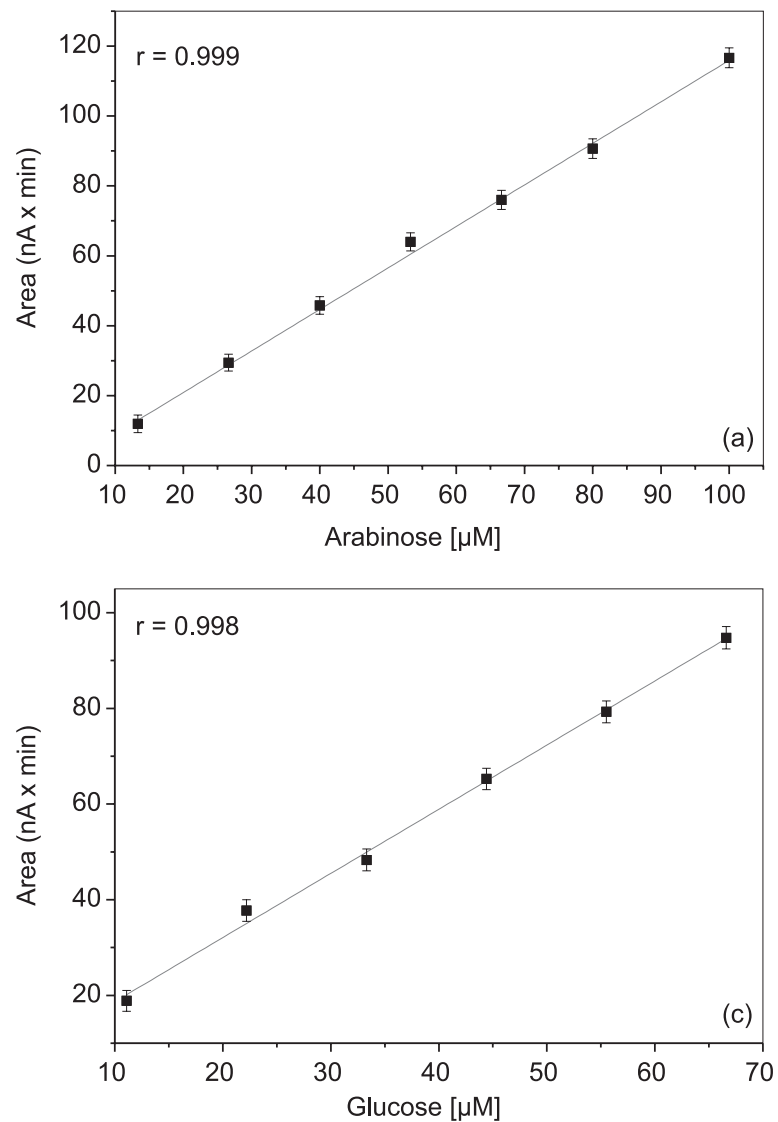

sample showed high concentrations of carbohydrates. The concentration of arabinose in the diluted aliquot was $1.4 \times 10^{-5} \mathrm{~mol} \mathrm{~L}^{-1}$ and the total concentration in the sample was $1.0 \times 10^{-3} \mathrm{~mol} \mathrm{~L}^{-1}$. The regression equation for galactose was $y=97.1+1.3 \times 10^{6} x$, with a linear correlation of 0.999 ; here, the sample dilution was found to be unnecessary because the sample concentration was within the studied range. As a result, the determined concentration for galactose was $7.2 \times 10^{-5} \mathrm{~mol} \mathrm{~L}^{-1}$. The curve of the standard addition method for glucose presented the regression equation $y=76.4+1.8 \times 10^{6} x$, with a linear correlation of 0.995 . The sample was diluted 70 times and the concentration of glucose in the diluted aliquot was $4.3 \times 10^{-5} \mathrm{~mol} \mathrm{~L}^{-1}$, while the total concentration in the sample was $3.0 \times 10^{-3} \mathrm{~mol} \mathrm{~L}^{-1}$. The linear regression equation for xylose was $y=44.8+1.3 \times 10^{6} x$, with a linear correlation of 0.998 . The sample was diluted 70 times and the concentration of xylose in the diluted aliquot was $3.5 \times 10^{-5} \mathrm{~mol} \mathrm{~L}^{-1}$, while the total concentration in the sample was $2.4 \times 10^{-3} \mathrm{~mol} \mathrm{~L}^{-1}$.

The standard addition method was performed on three different GCE/MWCNT/CoOOH electrodes in order to verify the reproducibility of detection.
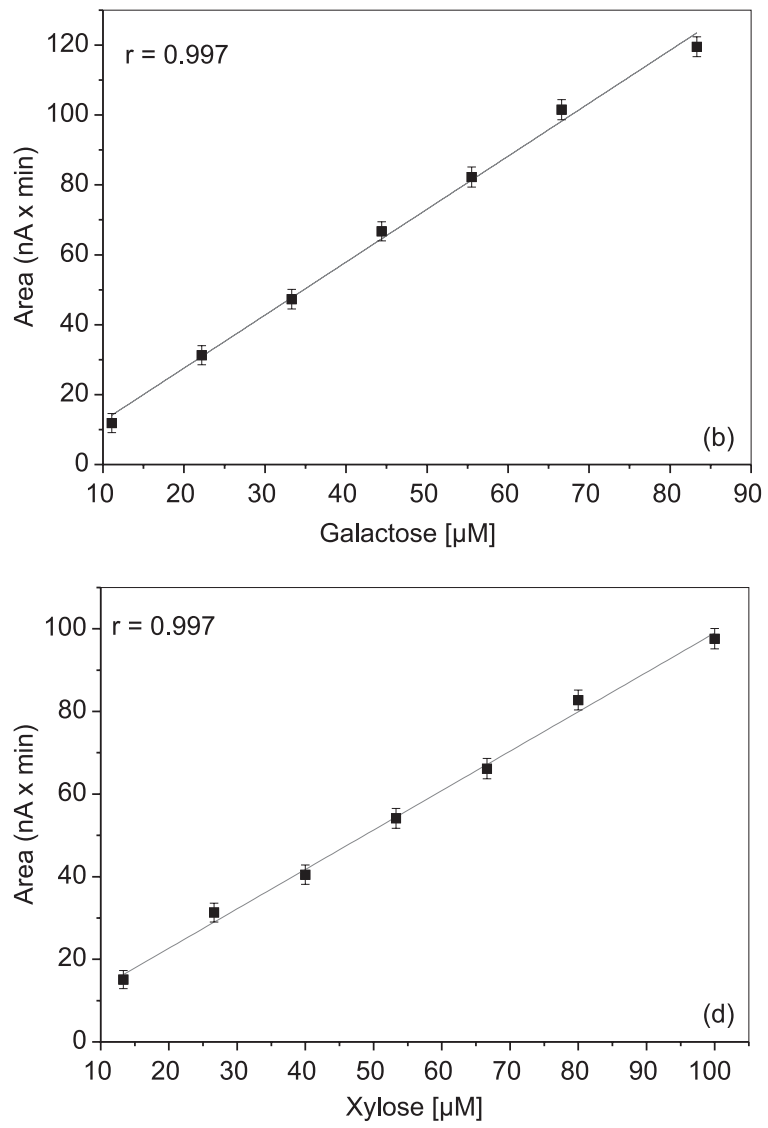

Figure 5. Calibration curve for (a) arabinose, (b) galactose, (c) glucose and (d) xylose. Detection potential of 0.58 V versus $\mathrm{Pd}$ for GCE/MWCNT/CoOOH electrode, mobile phase composition of $9 \%$ of $0.1 \mathrm{~mol} \mathrm{~L}^{-1} \mathrm{NaOH}$ and $91 \%$ of $\mathrm{H}_{2} \mathrm{O}$, flow of mobile phase of $1.0 \mathrm{~mL}$ min ${ }^{-1}$, column oven temperature of $25^{\circ} \mathrm{C}$ and detector temperature of $35^{\circ} \mathrm{C}$. 


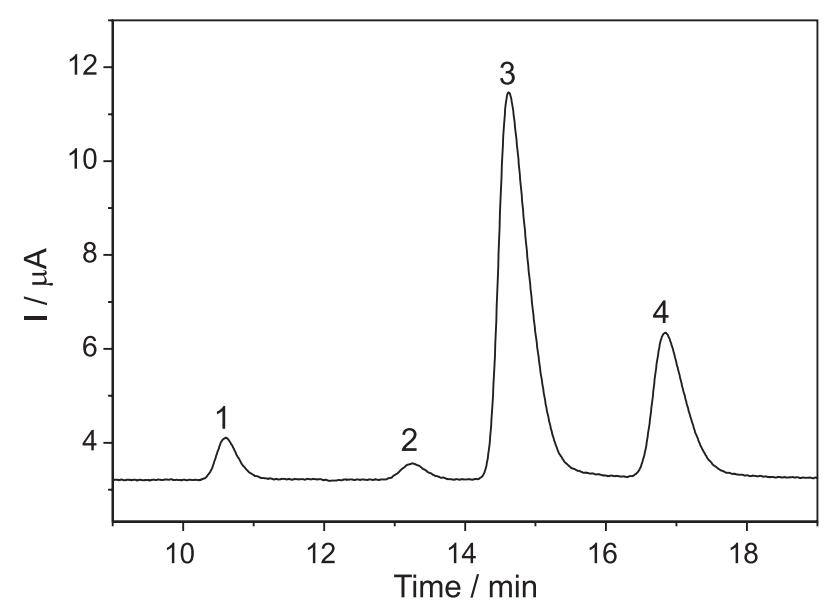

Figure 6. Chromatogram for a concentrated sample of hydrolyzed sugarcane bagasse containing (1) arabinose, (2) galactose, (3) glucose and (4) xylose. Detection potential of $0.58 \mathrm{~V}$ versus $\mathrm{Pd}$ for GCE/MWCNT/ CoOOH electrode; mobile phase composition: $9 \%$ of $0.1 \mathrm{~mol} \mathrm{~L}^{-1} \mathrm{NaOH}$ and $91 \%$ of $\mathrm{H}_{2} \mathrm{O}$; flow of mobile phase of $1.0 \mathrm{~mL} \mathrm{~min}^{-1}$; column oven temperature of $25^{\circ} \mathrm{C}$; and detector temperature of $35^{\circ} \mathrm{C}$.

After carrying out the standard addition method, a validation of the method was evaluated through the recovery studies for the carbohydrates, namely, arabinose, galactose, glucose and xylose. Three different solutions of the carbohydrates were injected, as shown in Table 3. The mean recovery for arabinose was $100.0 \%$, with a coefficient of variation $(\mathrm{CV})$ of $3.6 \%$; the average recovery

Table 3. Recoveries of carbohydrates using GCE/MWCNT/CoOOH electrode-based HPLC-RPAD technique $(\mathrm{n}=3)$

\begin{tabular}{|c|c|c|}
\hline $\begin{array}{l}\text { Amount added / } \\
\left(\mathrm{mol} \mathrm{L}^{-1}\right)\end{array}$ & $\begin{array}{l}\text { Amount found / } \\
\left(\mathrm{mol} \mathrm{L}^{-1}\right)\end{array}$ & Recorvery / \% \\
\hline \multicolumn{3}{|c|}{ Arabinose } \\
\hline $1.3 \times 10^{-5}$ & $1.2 \times 10^{-5}$ & $96.2 \pm 3.5$ \\
\hline $4.0 \times 10^{-5}$ & $4.1 \times 10^{-5}$ & $103.5 \pm 1.5$ \\
\hline $6.6 \times 10^{-5}$ & $6.7 \times 10^{-5}$ & $100.3 \pm 2.4$ \\
\hline \multicolumn{3}{|c|}{ Galactose } \\
\hline $1.1 \times 10^{-5}$ & $1.0 \times 10^{-5}$ & $96.4 \pm 2.1$ \\
\hline $3.3 \times 10^{-5}$ & $3.3 \times 10^{-5}$ & $99.8 \pm 1.5$ \\
\hline $5.5 \times 10^{-5}$ & $5.5 \times 10^{-5}$ & $99.5 \pm 1.4$ \\
\hline \multicolumn{3}{|c|}{ Glucose } \\
\hline $1.1 \times 10^{-5}$ & $9.2 \times 10^{-6}$ & $82.5 \pm 3.2$ \\
\hline $3.3 \times 10^{-5}$ & $3.2 \times 10^{-5}$ & $97.2 \pm 2.5$ \\
\hline $5.5 \times 10^{-5}$ & $5.5 \times 10^{-5}$ & $100.1 \pm 1.5$ \\
\hline \multicolumn{3}{|c|}{ Xylose } \\
\hline $1.3 \times 10^{-5}$ & $1.4 \times 10^{-5}$ & $108.2 \pm 2.1$ \\
\hline $4.0 \times 10^{-5}$ & $3.8 \times 10^{-5}$ & $94.3 \pm 2.5$ \\
\hline $6.6 \times 10^{-5}$ & $6.7 \times 10^{-5}$ & $100.9 \pm 1.9$ \\
\hline
\end{tabular}

aRecovery $(\%)=($ detected amount - original amount $) /$ added amount $\times 100$. for galactose was $98.5 \%$, with a $\mathrm{CV}$ of $1.9 \%$; the average recovery for glucose was $93.3 \%$, with a $\mathrm{CV}$ of $10.1 \%$; and xylose exhibited a mean recovery of $101.1 \%$, with a CV of $6.9 \%$. These results show that the method is suitable and has high reliability for the detection of carbohydrates in hydrolyzed sugarcane bagasse.

\section{Conclusions}

The glassy carbon electrode modified with carbon nanotubes containing nanoparticles of cobalt oxides (GCE/MWCNT/CoOOH) was successfully applied as an amperometric detector for the determination of carbohydrates by HPLC-PAD.

The new method developed in this work for pulsed amperometric detection of the four carbohydrates investigated here was found to be selective, sensitive, reproducible and reliable. These properties make the method an interesting alternative for further analytical applications involving sugarcane bagasse.

The GCE/MWCNT/CoOOH electrode was applied for the detection of samples of biomass hydrolysate, where the concentrations of arabinose, galactose, glucose and xylose determined in the sugarcane bagasse samples were $1.0 \times 10^{-3}, 7.2 \times 10^{-5}, 3.0 \times 10^{-3}$ and $2.4 \times 10^{-3} \mathrm{~mol} \mathrm{~L}^{-1}$, respectively.

The results demonstrate that the proposed method can be used for the detection of these carbohydrates without the need of derivatization. In addition, the method offers the advantage of detection with considerable accuracy and reliability, and without the interference of other electroactive species.

\section{Supplementary Information}

Supplementary information (containing details related to the energy dispersive spectroscopy (EDS) of the GCE/MWCNT/CoOOH electrode, the pulse sequence applied in the analysis of sugars with reverse pulsed amperometric detection (RPAD) using the GCE/ MWCNT/CoOOH electrode, and the chromatograms related to the studies of mobile phase concentration in the separation of carbohydrates) is available free of charge at http://jbcs.sbq.org.br as PDF file.

\section{Acknowledgments}

This work was financially supported by FAPESP (process No. 2011/19289-5, BEPE 2014/15557-3 and 2012/00258-5), CAPES process: AUX/PE/ PROEX/0486/2017 and CNPq process: 153855/2018-5. 
The authors are grateful to LMA-IQ for carrying out the SEM-FEG analysis.

\section{References}

1. Maugeri, L.; Busch, S.; McLain, S. E.; Pardo, L. C.; Bruni, F.; Ricci, M. A.; Biochim. Biophys. Acta 2017, 1861, 1486.

2. Biomass Research and Development; Summary of the Technical Advisory Committee Meeting; Washington, DC, USA, 2002, avaliable at https://biomassboard.gov/pdfs/faca_meeting_ summary_06-27-2002_final.pdf accessed in August 2019.

3. Wang, J.; Zhang, Z.; Jin, S.; Shen, X.; Fuel 2017, 192, 102.

4. Chatterjee, C.; Pong, F.; Sen, A.; Green Chem. 2015, 17, 40.

5. Kuo, C.-H.; Poyraz, A. S.; Jin, L.; Meng, Y.; Pahalagedara, L.; Chen, S. Y.; Kriz, D. A.; Guild, C.; Gudz, A.; Suib, S. L.; Green Chem. 2014, 16, 785.

6. Chen, G.; Qiu, J.; Xu, J.; Fang, X.; Liu, Y.; Liu, S.; Wei, S.; Jiang, R.; Luan, T.; Zeng, F.; Zhu, F.; Ouyang, G.; Chem. Sci. 2016, 7, 1487.

7. Filip, M.; Vlassa, M.; Coman, V.; Halmagyi, A.; Food Chem. 2016, 199, 653 .

8. Costa, M. P.; Frasao, B. D. S.; Lima, B. R. C. D. C.; Rodrigues, B. L.; Junior, C. A. C.; Talanta 2016, 152, 162.

9. Santos, F. C. U.; Paim, L. L.; Silva, J. L.; Stradiotto, N. R.; Fuel 2016, 163, 112.

10. Yao, L.; Chen, C.; Zheng, X.; Peng, Z.; Yang, H.; Xie, Y.; BioResources 2016, 11, 6692.

11. Barragan, T. C.; Kubota, L. T.; Anal. Chim. Acta 2016, 906, 89.

12. Fa, Y.; Yang, H.; Ji, C.; Cui, H.; Zhu, X.; Du, J.; Gao, J.; Anal. Chim. Acta 2013, 798, 97.

13. Fedorowski, J.; Lacourse, W. R.; Anal. Chim. Acta 2015, 861, 1.

14. Liang, P.; Sun, M.; He, P.; Zhang, L.; Chen, G.; Food Chem. 2016, 190, 64.

15. Ma, C.; Sun, Z.; Chen, C.; Zhang, L.; Zhu, S.; Food Chem. 2014, 145, 784.

16. Matías, J.; González, J.; Royano, L.; Barrena, R. A.; Biomass Bioenergy 2011, 35, 2006.

17. Sevcik, R. S.; Mowery, R. A.; Becker, C.; Chambliss, C. K.; J. Chromatogr. A 2011, 1218, 1236.

18. Corradini, C.; Cavazza, A.; Bignardi, C.; Int. J. Carbohydr. Chem. 2012, 2012, ID 487564.

19. Rodríguez-Gómez, R.; Jiménez-Díaz, I.; Zafra-Gómez, A.; Morales, J. C.; Talanta 2015, 144, 883.
20. Gangola, M. P.; Jaiswal, S.; Khedikar, Y. P.; Chibbar, R. N.; Food Chem. 2014, 154, 127.

21. Toghill, K. E.; Compton, R. G.; Int. J. Electrochem. Sci. 2010, $5,1246$.

22. Wang, G.; He, X.; Wang, L.; Gu, A.; Huang, Y.; Fang, B.; Geng, B.; Zhang, X.; Microchim. Acta 2012, 180, 161.

23. Sá, A. C.; Sedenho, G. C.; Paim, L. L.; Stradiotto, N. R.; Electroanalysis 2018, 30, 128.

24. Edwards, G. A.; Bergren, A. J.; Porter, M. D. In Handbook of Electrochemistry; Zoski, C., ed.; Elsevier: Amsterdam, 2007, p. 295-323.

25. Toghill, K. E.; Xiao, L.; Phillips, M. A.; Compton, R. G.; Sens. Actuators, B 2010, 147, 642.

26. Bohua, W. E. N.; Shichao, Z.; Hua, F.; Rare Met. 2011, 30, 661.

27. Zhu, L.; Tian, C.; Zhai, J.; Yang, R.; Sens. Actuators, B 2007, 125, 254.

28. Rasband, W. S.; ImageJ, version 1.52a; U. S. National Institutes of Health, Bethesda, Maryland, USA, 2015.

29. Liu, Z. J.; Yuan, Z. Y.; Zhou, W.; Peng, L. M.; Xu, Z.; Phys. Chem. Chem. Phys. 2001, 3, 2518.

30. Salimi, A.; Hallaj, R.; Soltanian, S.; Mamkhezri, H.; Anal. Chim. Acta 2007, 594, 24.

31. Salimi, A.; Mamkhezri, H.; Hallaj, R.; Soltanian, S.; Sens. Actuators, B 2008, 129, 246.

32. Sluiter, J. B.; Ruiz, R. O.; Scarlata, C. J.; Sluiter, A. D.; Templeton, D. W.; J. Agric. Food Chem. 2010, 58, 9043.

33. Moura, S. L.; Moraes, R. R.; Santos, M. A. P.; Pividori, M. I.; Lopes, J. A. D.; Moreira, D. L.; Zucolotto, V.; Júnior, J. R. S.; Sens. Actuators, B 2014, 202, 469.

34. Cataldi, T. R. I.; Casella, I. G.; Desimoni, E.; Anal. Chim. Acta 1992, 270, 161.

35. Casella, I. G.; Gatta, M.; J. Electroanal. Chem. 2002, 534, 31.

36. Templeton, D. W.; Quinn, M.; Van Wychen, S.; Hyman, D.; Laurens, L. M. L.; J. Chromatogr. A 2012, 1270, 225.

37. Zhang, S.; Li, C.; Zhou, G.; Che, G.; You, J.; Suo, Y.; Carbohydr. Polym. 2013, 97, 794.

38. Burana-Osot, J.; Soonthornchareonnon, N.; Chaidedgumjorn, A.; Hosoyama, S.; Toida, T.; Carbohydr. Polym. 2010, 81, 461.

39. Lorenz, D.; Erasmy, N.; Akil, Y.; Saake, B.; Carbohydr. Polym. 2016, $140,181$.

40. Sá, L. R. V.; Oliveira, M. A. L.; Cammarota, M. C.; Matos, A.; Ferreira-Leitão, V. S.; Int. J. Hydrogen Energy 2011, 36, 15177.

Submitted: April 8, 2019

Published online: August 27, 2019 